\title{
Noninvasive Electrocardiographic Imaging Diagnosis of Brugada Syndrome
}

\author{
Maria Chaykovskaya ${ }^{1}$, Michail Chmelevsky $^{1}$, Boris Rudic $^{2}$, Erol Tueluemen ${ }^{2}$, Vitaly Kalinin ${ }^{1}$ \\ ${ }^{1}$ EP Solutions SA, Yverdon-les-Bains, Switzerland \\ ${ }^{2}$ Mannheim University Clinic, Mannheim, Germany
}

\begin{abstract}
Brugada syndrome (BrS) is a well-known inherited heart disease with a high risk of a sudden cardiac death (SCD) in young male patients. Thy only way to make a diagnosis is standard ECG. The spectrum of repolarization changes between normal ECG and BrS diagnostic criteria, are called BrS-like ECGs. They occur due to nonspecific right bundle brunch conduction disorders. Patients with this abnormal ECG are always a challenge for a doctor - is there a potentially fatal diagnosis or variant of normal ECG.
\end{abstract}

\section{Introduction}

Electrocardiographic phenomena of right bundle brunch block (RBBB) with ST-segment elevation was first described in 1953 in a little boy with recurrent syncope [1]. His smaller sister with similar ECG changes and symptoms died at the age of 2 despite implanted pacemaker and antiarrhythmic drug therapy. In 1992 brothers Pedro and Joseph Brugada based on 8 clinical cases proposed new syndrome of ECG changes associated with sudden cardiac death [2]. At 2002, by group of experts [3], there were defined three types of $\mathrm{BrS}$, depends on ST-T segment morphology, amplitude of elevation. Second consensus conference [4] conclude that only 1 type correlates with life threatening arrhythmias, while other types are nondiagnostic. All suspicious but nondiagnostic variants were called BrSlike and required further investigation.

In 1998 genetic tests revealed mutation in SCN5A gene [5]. Later 10 more genes were associated with $\mathrm{BrS}$ phenotype. Mostly they encode sodium channels, but there are some genes, encoded calcium and potassium channels as well. BrS is an autosomal dominant disease with incomplete penetrance, which means that even carriers of $\mathrm{BrS}$ genotype can never show typical phenotype and do not have the disease. Genetic tests go positive for causative mutation in about one third of all patients. In vast majority of patients, genetic cause of BrS stays unknown. Thus, clinical evaluation always goes first.

Patients with once registered 1 type $\mathrm{BrS}$ could have nondiagnostic phenotype on other day. Physiological conditions (autonomic tone) are thought to be the buffer between genotype and phenotype. There is a number of reports describing BrS ECG pattern appearance in people under different physiological conditions, such as exercise, fever, drug administration. Drug test with sodium channel blocker enables to unmask BrS in some patients. Its diagnostic value depends on drug used, mutation, autonomic tone, lead position [6]. Best profile of specificity and sensitivity shoves ajmaline [7] and flecainide [8], in which positive predictive value was reported more than $90 \%$ and negative predictive value from 30 to $83 \%$ [9]. Other drugs with sodium blocking activity could revel to BrS phenotype. The full list of them is described on the website brugadadrugs.org. All patients with BrS should avoid these medicine, because sodium channel blockage may lead not only to ECG changes, but also to clinical manifestation with ventricular arrhythmias.

Mechanism of arrhythmias and ECG development many years was the matter of debate. Too independent groups after series of experiments in silico, reported opposite hypothesis: repolarization disorder hypothesis [10] and depolarization disorder hypothesis [11]. Real breakthrough was made after cardiac catheterization and electrophysiological study in $\mathrm{BrS}$ patient with recurrent ventricular fibrillation episodes. So called electrophysiological substrate was found [12,13]. The area of abnormal electrogramms was located in anterior aspect of right ventricular outflow tract (RVOT). The abnormalities of electrogramms were the following: low voltage, prolonged duration and fractionated late potentials beyond ventricular complex. The same characteristics of electrogramms in RVOT in different patients with BrS enables to identify the substrate, and later, to eliminate this substrate with radiofrequency ablation. The similar picture of arrhythmogenic substrate was obtained using noninvasive electrocardiographic imaging $[14,15]$. They found low amplitude of electrogramms, fragmentation, slow discontinuous conduction, delayed RVOT activation and ST segment elevation and inverted $\mathrm{T}$ wave of reconstructed electrogramms.

The compromise between two confronting groups was achieved by providing confirmation of both repolarization and depolarization disorders. The huge step forward was described with eliminating of arrhythmogenic substrate and normalization of ECG and absence of ventricular arrhythmias in patient with 
repetitive electrical storms (recurrence of VF more than 3 times per day) [16].

Prevalence in Asia of $\mathrm{BrS}$ in adults is relatively higher than in West population $(0,15 \%$ vs $0,02 \%)$. It seems like there is some ethnical modulation of gene polymorphism, causing the disease [17]. Despite the low prevalence, $\mathrm{BrS}$ is responsible up to $20 \%$ of all sudden cardiac deaths in young population, with absence of structural heart disease [18]. The symptoms of the disease are the symptoms of ventricular arrhythmias. In case of nonsustained ventricular tachycardia or ventricular fibrillation, patient may develop dizziness, palpitations and syncope. In case of sustained VF patient develop cardiac arrest. Syncope and spontaneous type 1 ECG pattern are risk factors of SCD, according to current guidelines. Cardioverter-defibrillator should be implanted in these patients for primary prevention reasons. We have conflicting data on other proposed risk factors. Risk evaluation and management of $\mathrm{BrS}$ patients remains the matter of debate. BrS clinical manifestation occurs on the forth decade of life, in healthy individuals. In the absence of symptoms, prognosis is favorable and annual death rate is expected to be less than $0.5 \%$ [17]. In case of syncopes and documented VF episodes, annual recurrence rate is estimated to be $11 \%$ [19]. Cardiac arrest could be the first sign of BrS. Thereby diagnostic and risk evaluation are still needs further investigations.

\section{Materials and Methods}

We examined 10 consistent patients with BrS-like ECGs. It was a prospective 2 center study, lasting for 3 years (Petrovsky National Research Centre of Surgery, Moscow, Russia and Mannheim University Clinic, Mannheim, Germany). All patients were asymptomatic. One with family history of $\mathrm{BrS}$ and positive genetic screening for SCN5A mutation (c.1233del). Predominantly males $(\mathrm{n}=8)$, age median was $37 \pm 11,4 \mathrm{y}$. The aim of our study was to determine the difference between RBBB and $\mathrm{BrS}$ in patients with Brugada-like ECG noninvasively

We perform noninvasive ECGI using AMYCARD system (EP Solution SA, Yverdon-les-Bains, Switzerland), which allows to reconstruct epicardial and endocardial unipolar electrogramms noninvasively, using heart/torso anatomy from computing tomography of cardiac magnetic resonance imaging and body surface ECG of 224 channels.

\section{Results}

Standard 12-lead and polyECG recordings were made at the baseline conditions and during drug challenge, aimed to unmask typical BrS ECG pattern. In half $(n=5)$ of our group test was positive and obtained ECG changes met diagnostic criteria of $\mathrm{BrS}$, while in others sodium channel blockage does not impact on ECG.

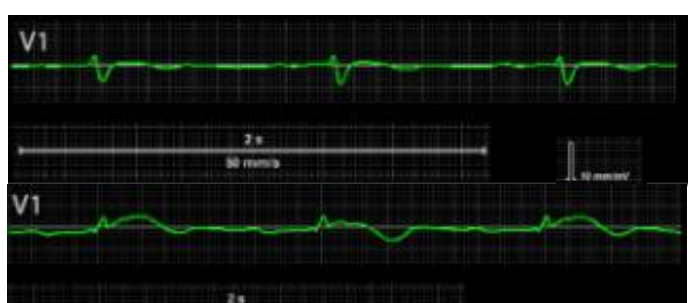

Picture1. Drug-induced 1 type BrS ECG: before and after drug challenge.
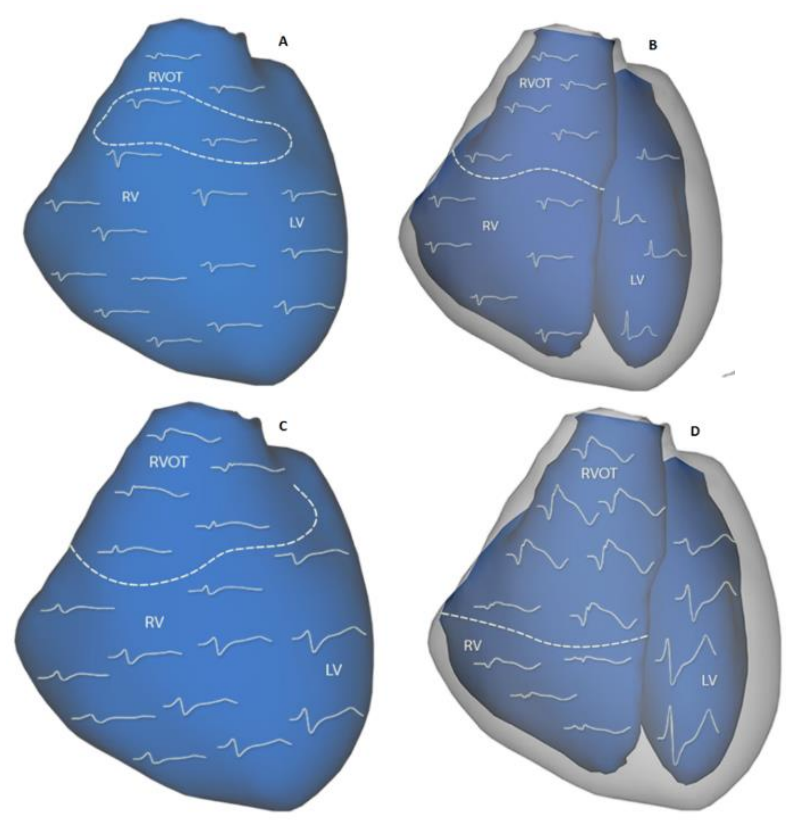

Picture 2. Morphology of epicardial and endocardial electrogramms in drug-induced type 1 patient: A and B - before drug challenge; $\mathrm{C}$ and $\mathrm{D}$ - after drug challenge.

While baseline standard ECG looks very similar in all 10 patients (ST segment elevation $<2 \mathrm{mV}$ with a following negative $\mathrm{T}$ wave), morphology of local unipolar electrogramms in right ventricle outflow tract (RVOT) differ a lot. At baseline condition patients with positive drug test, have morphological anomalies inherent to BrS patients in RVOT. Such as ST segment elevation $>2 \mathrm{mV}$, fragmentation (more than three distinct peaks) and low voltage. Median (Me) of amplitude of ST segment elevation on the epicardium was $2,3 \mathrm{mV}$ in $\mathrm{BrS}$ patients versus $0,1 \mathrm{mV}$ in patients with negative drug test $(\mathrm{p}=0,008)$, and $2,6 \mathrm{mV}$ vs $0,2 \mathrm{mV}$ on endocardium. Fragmentation of electrogramms was registered in all $\mathrm{BrS}$ patients on the epicardial surface $(n=5)$. The amplitude of electrogramms was lower on the epicardium surface in $\mathrm{BrS}$ patients $\mathrm{Me}=0,1 \mathrm{mV}$ vs $\mathrm{Me}=3,6 \mathrm{mV}$ in healthy individuals, but the difference was not statistically significant (table 1). 


\section{Discussion}

ICD implantation for a long time stays the golden standard or care of $\mathrm{BrS}$ patients [20]. In presence of syncopes or after aborted cardiac arrest, this was the only way of SCD prevention. Antiarrhythmic drugs do not show any effect on ventricular arrhythmias in these patients.

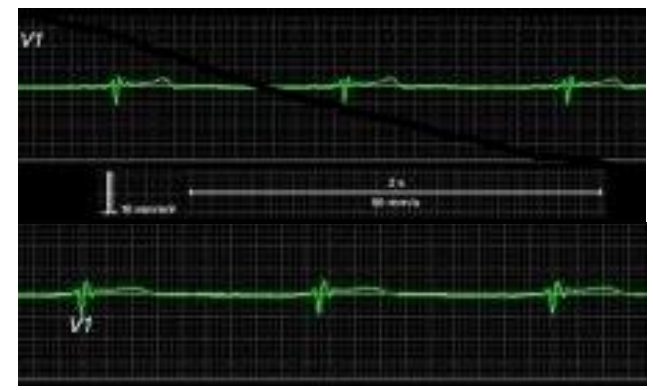

Picture 3. Brugada-like ECG: ECG: before and after drug challenge.
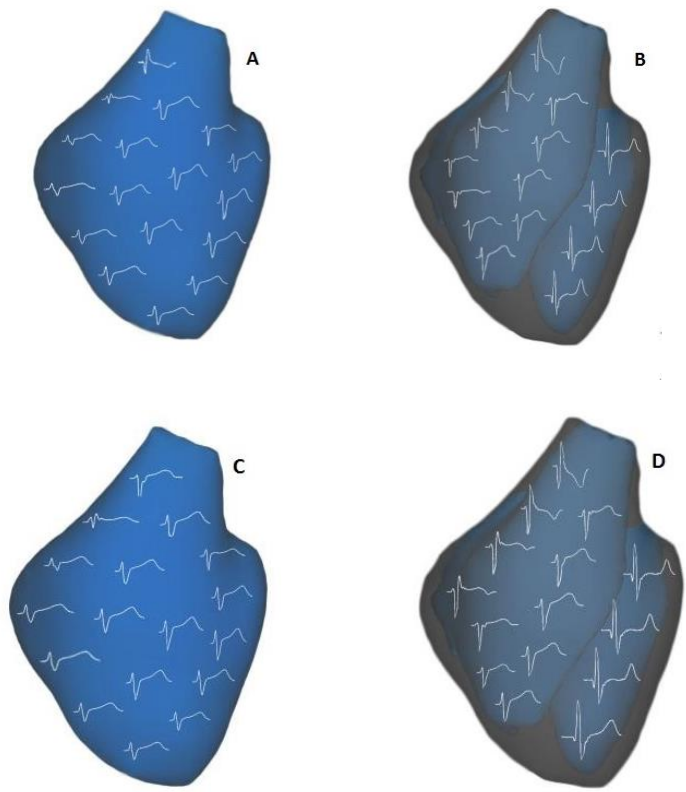

Picture 4. Morphology of epicardial and endocardial electrogramms in Brugada-like ECG patient: A and B before drug challenge; $\mathrm{C}$ and $\mathrm{D}$ - after drug challenge.

Discussing with patient his or her prognosis and death rate is a hard talk to make. Especially in situation, when patient have spontaneous ECG pattern, but no risk factors. This is a grey zone, whether SCD occurs and when would it happened? Some of patients prefers double confidence and forces the doctor to the unnecessary ICD implantation. Device is technically lifesaving, but quality of life is compromised with inappropriate shocks.

But nowadays we have promising experience of arrhythmia substrate elimination using invasive or noninvasive navigation. This approach improves quality of life, and practically healing patients. The question is, should we ablate asymptomatic patients or not. Is it safe enough to perform cardiac catheterization and epicardial ablation in people with annual rick of SCD $0,5 \%$ ?

The other question is diagnostic evaluation. Can we define patients with BrS-like ECG between healthy individuals and sick people? If we can, are there any additional factors for risk stratification?

With our study we find the answer for one of these questions. Using ECGI alone or in combination with standard drug test we can improve diagnostics of BrS.

\section{Conclusion}

All BrS patients has zone of abnormal electrograms in epicardial and endocardial aspects of RVOT, irrespective to the current ECG picture. Coved STsegment elevation of rEGs, magnitude $\geq 2 \mathrm{mV}$ might be strong independent predictor of $\mathrm{BrS}$ in patients with nondiagnostic ECG

\section{References}

[1] HL Osher, L Wolff. "Electrocardiographic pattern simulating acute myocardial injury" Am J Med Sci. 1953. Vol. 226.P. 541-545.

[2] P Brugada, J Brugada. "Right Bundle Branch Block, Persistent ST Segment Elevation and Sudden Cardiac Death: A Distinct Clinical and Electrocardiographic Syndrome" JACC. 1992. Vol. 20 (6). P. 1391-1396.

[3] AA Wilde, C Antzelevitch, M Borggrefe, et al. "Proposed Diagnostic Criteria for the Brugada Syndrome: Consensus Report" Circulation. 2002. Vol. 106. P. 2514-2519.

[4] Antzelevitch C, Brugada P, Borggrefe M, et.al. "Brugada syndrome: report of the second consensus conference: endorsed by the Heart Rhythm Society and the European Heart Rhythm Association" Circulation. 2005. Vol. 111(5). - P. 659670.

[5] Q Chen, GE Kirsch, D Zhang, et al. "Genetic basis and molecular mechanism for idiopathic ventricular fibrillation" Nature. 1998.Vol. 392. P. 293-296.

[6] MN Obeyesekere , GJ Klein, S Modi, et al. "How to perform and interpret provocative testing for the diagnosis of Brugada syndrome, long-QT syndrome, and catecholaminergic polymorphic ventricular tachycardia" Circ Arrhythm Electrophysiol. 2011 Dec;4(6):958-64.

[7] K. Hong, J. Brugada, A. Oliva, et al. "Value of electrocardiographic parameters and ajmaline test in the diagnosis of Brugada syndrome caused by SCN5A mutations" Circulation., 110 (2004), pp. 3023-3027

[8] G. Meregalli, J. Ruijter, N. Hofman, et al. "Diagnostic value of flecainide testing in unmasking SCN5A-related Brugada syndrome" J Cardiovasc Electrophysiol., 17 (2006), pp. 857-864

[9] M Nishizaki, N Yamawake, H Sakurada, et al. "ECG interpretation in Brugada syndrome" Journal of Arrhythmia Volume 29, Issue 2, April 2013, Pages 56-64 
[10] C Antzelevitch. "Ion and channels and ventricular arrhythmias: cellular and ionic mechanisms underlying the Brugada syndrome" Curr Opin Cardiol 1999. Vol. 14. P. 274279.

[11] PG Postema, PF van Dessel, JM de Bakker, et al. "Slow and discontinuous conduction conspire in Brugada syndrome a right ventricular mapping and stimulation study" Circ Arrhythm Electrophysiol. 2008. Vol. 1. P. 379-386.:

[12] M Haïssaguerre, F Extramiana, M Hocini, et al. "Mapping and ablation of ventricular fibrillation associated with long-QT and Brugada byndrome" Circulation. 2003. Vol. 108. P. 925928.

[13] K Nademanee, G Veerakul, P Chandanamattha, et al. "Prevention of Ventricular Fibrillation Episodes in Brugada Syndrome by Catheter Ablation Over the Anterior Right Ventricular Outflow Tract Epicardium Clinical Perspective" Circulation. 2011. Vol. 123. P. 1270-1279.

[14] J Zhang, F Sacher, K Hoffmayer, et al. "Cardiac Electrophysiologic Substrate Underlying the ECG Phenotype and Electrogram Abnormalities in Brugada Syndrome Patients" Circulation. 2015. Vol. 131. P. 1950-1959.

[15] B Rudic, M Chaykovskaya, A Tsyganov, et al

"Simultaneous Non-Invasive Epicardial and Endocardial Mapping in Patients With Brugada Syndrome: New Insights Into Arrhythmia Mechanisms" J Am Heart Assoc. 2016 Nov 14;5(11). pii: e004095.
[16] J Brugada, C Pappone, A Berruezo. "Brugada Syndrome Phenotype Elimination by Epicardial Substrate Ablation" Circ Arrhythm Electrophysiol. 2015. Vol. 8 (6). P. 1373-1381.

[17] S Kamakura. "Epidemiology of Brugada syndrome in Japan and rest of the world" Journal of ArrhythmiaVolume 29, Issue 2, April 2013, Pages 52-55

[18] J Brugada, R Brugada, C Antzelevitch, et al. "Long-term follow-up of individuals with the electrocardiographic pattern of right bundle-branch block and ST-segment elevation in precordial leads V1 to V3" Circulation. 2002. Vol. 105(1). P. 73-78

[19] B Benito, R Brugada, J Brugada, et al. "Brugada syndrome" Prog Cardiovasc Dis. 2008.Vol 51. - P. 1-22.

[20] SG Priori, C Blomstrom-Lundqvist, A Mazzanti, et al. "2015 ESC Guidelines for the management of patients with ventricular arrhythmias and the prevention of sudden cardiac death" European Heart Journal. - 2015. - Vol. 36. - P. 2793 2867.

Address for correspondence.

Maria Chaykovskaya

Av. Des Sciences 13, 1400 Yverdon-les-Bains, Switzerland maria.chaykovskaya@ep-so;utions.ch

Table 1. Characteristics of electrogramms in RVOT in patients with BrS like ECG

\begin{tabular}{|c|c|c|c|c|c|c|}
\hline \multirow[t]{3}{*}{ Parameters } & \multirow[t]{3}{*}{ Heart surface } & \multicolumn{4}{|c|}{ BrS-like ECG, $n=10$} & \multirow[t]{3}{*}{$\mathbf{p}$} \\
\hline & & \multicolumn{2}{|c|}{$\begin{array}{l}\text { Positive drug test, } \\
\mathrm{n}=5\end{array}$} & \multicolumn{2}{|c|}{ Negative drug test, $\mathrm{n}=5$} & \\
\hline & & $\begin{array}{l}\mathrm{Me} \\
(\mathrm{Q} 1-\mathrm{Q} 3)\end{array}$ & Min-Max & $\begin{array}{l}\mathrm{Me} \\
(\mathrm{Q} 1-\mathrm{Q} 3)\end{array}$ & Min-Max & \\
\hline \multirow[t]{2}{*}{$\begin{array}{l}\text { Surface area of ST } \\
\text { segment elevation, } \\
\text { mm }^{2}\end{array}$} & Epi & $\begin{array}{l}1208 \\
(1125- \\
1643)\end{array}$ & $0-2683$ & - & - & $\mathbf{0 , 0 3 2}$ \\
\hline & Endo & $\begin{array}{l}1935 \\
(1087- \\
3483)\end{array}$ & $0-4582$ & - & - & 0,019 \\
\hline \multirow{2}{*}{$\begin{array}{l}\text { ST segment } \\
\text { elevation amplitude, } \\
\text { mV }\end{array}$} & Epi & $\begin{array}{l}2,3 \\
(2,1-2,6)\end{array}$ & $0,1-3,7$ & $\begin{array}{l}0,1 \\
(0,1-0,1)\end{array}$ & $0,1-0,2$ & 0,008 \\
\hline & Endo & $\begin{array}{l}2,6 \\
(2,1-2,7)\end{array}$ & $0,4-3,6$ & $\begin{array}{l}0,2 \\
(0,1-0,4)\end{array}$ & $0,3-0,6$ & 0,008 \\
\hline \multirow[t]{2}{*}{$\begin{array}{l}\text { Surface area of } \\
\text { electrogramms } \\
\text { fragmentation, } \mathbf{m m}^{2}\end{array}$} & Epi & $\begin{array}{l}1422 \\
(1232- \\
1554)\end{array}$ & $\begin{array}{l}1023- \\
1607\end{array}$ & - & - & 0,841 \\
\hline & Endo & $\begin{array}{l}0 \\
(0-204)\end{array}$ & $0-2386$ & - & - & 0,317 \\
\hline \multirow[t]{2}{*}{$\begin{array}{l}\text { Mean voltage of } \\
\text { electrogramms, } \mathrm{mV}\end{array}$} & Epi & $\begin{array}{l}0,1 \\
(0,1-0,6)\end{array}$ & $0,1-0,7$ & $\begin{array}{l}3,6 \\
(2,7-4,3)\end{array}$ & $2,1-4,7$ & 0,116 \\
\hline & Endo & $\begin{array}{l}5,6 \\
(2,3-6,5)\end{array}$ & $1,0-8,9$ & $\begin{array}{l}6,8 \\
(4,8-6,8)\end{array}$ & $1,8-9,0$ & 0,712 \\
\hline
\end{tabular}

